\title{
Anxiolytic Activity of the MGLU2/3 Receptor Agonist LY354740 on the Elevated Plus Maze is Associated with the Suppression of Stress-Induced c-Fos in the Hippocampus and Increases in c-Fos Induction in Several Other Stress-Sensitive Brain Regions
}

\author{
A-M Linden', SJ Greene', M Bergeron' and DD Schoepp*,' \\ 'Neuroscience Research Division, Lilly Research Laboratories, Eli Lilly and Company, Indianapolis, IN, USA
}

\begin{abstract}
LY354740 is a potent and selective agonist for group II metabotropic glutamate (mGlu) receptors, mGlu2 and mGlu3 receptors, with anxiolytic activity in several animal models of anxiety, including the elevated plus maze (EPM) test. Here, we studied neuronal activation in mouse brain after EPM exposure in saline- and LY354740-treated mice using c-Fos immunoreactivity as a marker. The effect of LY354740 on c-Fos expression was also studied in cage control (no EPM) mice. Pretreatment with LY354740 (20 mg/kg, s.c.) produced robust anxiolytic behavior on the EPM. LY354740 administration decreased EPM-induced increases in c-Fos expression in the CA3 of the hippocampus, while having no significant effects on basal c-Fos expression in the hippocampus. LY354740 administration significantly increased c-Fos expression in specific limbic regions, including the lateral division of the central nucleus of the amygdala (CeL), lateral parabrachial nucleus, locus coeruleus, and Edinger-Westphal nucleus, whether or not animals were exposed to the EPM. Moreover, LY354740 administration per se significantly increased c-Fos expression in regions processing sensory information, including the paraventricular and lateral geniculate nucleus of the thalamus as well as the nucleus of the optic tract and superior colliculus. In particular, the suppression of fear-evoked neuronal activity in the hippocampus and drug-induced increases in neuronal activation in the CeL have been previously linked to the anxiolytic effects of clinically effective drugs such as benzodiazepines, and thus may contribute to anxiolytic actions of LY354740 in animal models and human anxiety patients.
\end{abstract}

Neuropsychopharmacology (2004) 29, 502-513, advance online publication, 24 December 2003; doi:I0.1038/sj.npp. I 30032 I

Keywords: hippocampus; central nucleus of the amygdala; Edinger-Westphal; c-Fos; metabotropic glutamate receptors; anxiolytic; LY354740

\section{INTRODUCTION}

The excitatory neurotransmitter glutamate acts through ligand-gated ion channels and G-protein-coupled metabotropic glutamate (mGlu) receptors. Eight known subtypes of mGlu receptors can be divided into three groups (Group I: mGlu1, 5; Group II: mGlu2, 3; Group III: mGlu4, 6, 7, 8) based on their molecular structure, second messenger system, and pharmacological profile (Conn and Pin, 1997; Schoepp et al, 1999a). Group II mGlu receptors are localized

*Correspondence: DD Schoepp, Neuroscience Research Division, Lilly Research Laboratories, Eli Lilly and Company, Lilly Corporate Center, drop code 0510, Indianapolis, IN 46285, USA, Tel: + 317276 6316, Fax: + 317276 7600, Email: schoepp@lilly.com

Received 24 June 2003; revised 20 August 2003; accepted 25 August 2003

Online publication: 08 September 2003 at http://www.acnp.org/ citations/Npp09080303274/default.pdf presynaptically outside the active zone of axon terminals, and also in postsynaptic neurons and glia (mGlu3 receptor) (Shigemoto et al, 1997; Tamaru et al, 2001). Electrophysiological studies have demonstrated that the activation of presynaptic mGlu2/3 receptors negatively modulates the release of glutamate providing feedback that prevents excessive glutamate release (reviewed by Anwyl, 1999; Cartmell and Schoepp, 2000). mGlu2/3 receptors may also function as heteroreceptors controlling the release of $\gamma$-aminobutyric acid (GABA) and other neurotransmitters, including monoamines (eg dopamine) and neuropeptides (Cartmell and Schoepp, 2000). In addition to the regulation of neurotransmitter release, activation of postsynaptic mGlu2/3 receptors can negatively modulate neuronal excitability and plasticity via intracellular mechanisms such as modulation of ion channels (eg potassium) and induction of long-term synaptic depression (Anwyl, 1999). 
Based on animal and early human data, modulation of excitatory neurotransmission via mGlu2/3 receptors is a novel approach to treat anxiety, as well as other psychiatric disorders (Schoepp, 2001; Schoepp and Marek, 2002; Schoepp et al, 2003). (1S,2S,5R,6S)-2-aminobicyclo [3.1.0] hexane-2,6-dicarboxylic acid (LY354740) is a selective and potent agonist for mGlu2 and mGlu3 receptors (Monn et al, 1997). It activates human cloned mGlu2 and mGlu3 receptors in non-neuronal cells with $\mathrm{EC}_{50}$ values of 5 and $24 \mathrm{nM}$, respectively, while $\mathrm{EC}_{50}$ values for other mGlu receptors were $36 \mu \mathrm{M}$ (mGlu8) or higher $\left(\mathrm{EC}_{50}>100 \mu \mathrm{M}\right.$ for mGlu1, 5, 4, 7) (reviewed by Schoepp et al, 1999b). LY354740 produces anxiolytic-like effects in several animal models of anxiety, including fear-potentiated startle (Helton et al, 1998), elevated plus maze (EPM) (Monn et al, 1997; Helton et al, 1998; Ferris et al, 2001), conflict drinking test (Klodzinska et al, 1999), and stress-induced hyperthermia (Spooren et al, 2002). LY354740 is also active in an animal model of panic disorder (Shekhar and Keim, 2000). In humans, LY354740 reduced $\mathrm{CO}_{2}$-induced panic anxiety (Levine et al, 2001; Schoepp et al, 2003) and produced anxiolytic effects in the fear-potentiated startle paradigm (Grillon et al, 2003).

LY354740 binds to mGlu2/3 receptors primarily throughout the forebrain of rats (Schaffhauser et al, 1998; Wright et al, 2001; Schoepp et al, 2003). In brain synapses such as the central nucleus of the amygdala (Neugebauer et al, 2000), hippocampal perforant path (Kilbride et al, 1998, 2001), medial prefrontal cortex (mPFC) (Marek et al, 2000), nucleus accumbens (Robbe et al, 2002), and substantia nigra (Bradley et al, 2000), LY354740 has been shown to suppress evoked glutamate excitatory synaptic potentials/ currents (reviewed by Schoepp et al, 2003). In particular, the intra-amygdalar injection of LY354740 disrupted fearpotentiated startle (Walker et al, 2002), and intrahippocampal injection of LY354740 produced an anticonflict effect in the Vogel drinking test (Tatarczynska et al, 2001), suggesting that these regions may be involved in the anxiolytic actions of LY354740 when it is administered systemically.

The immediate early gene c-Fos is induced in cells in vivo and in vitro by membrane depolarization (reviewed by Hughes and Dragunow, 1995). The induction of c-Fos mRNA or protein has been widely used as a marker to map neuronal populations activated in vivo after pharmacological treatments or environmental stimuli. Exposure to EPM anxiety has been reported to moderately induce c-Fos expression in several limbic brain regions (Graeff et al, 1993; Duncan et al, 1996; Hinks et al, 1996). Stronger and more widespread c-Fos induction is observed after more severe stressors (Stone and Zhang, 1995; Duncan et al, 1996; Chowdhury et al, 2000). Moreover, the suppression of stress-induced c-Fos expression in the rat brain has been associated with the anxiolytic effects of benzodiazepines in the fear-conditioning model of anxiety (Beck and Fibiger, 1995). Furthermore, benzodiazepine administration per se increases c-Fos expression in populations of neurons associated with modulation of stress/fear, including GABAergic cells of the lateral central amygdala (Hitzemann and Hitzemann, 1999).

In order to study how systemic administration of the mGlu2/3 agonist affects neuronal excitability in the brain and to investigate brain regions that may mediate its anxiolytic activity, control mice were treated with saline or LY354740 (20 mg/kg, s.c.) and their brains were collected for c-Fos immunohistochemistry $2.5 \mathrm{~h}$ later. We also investigated if the behavioral effects of LY354740 on EPM are associated with changes in EPM-induced c-Fos expression. Here, mice were pretreated with saline or LY354740 (0.5 h), their behavior was briefly monitored on EPM, and brains were collected for c-Fos immunohistochemistry $2 \mathrm{~h}$ after EPM exposure.

\section{EXPERIMENTAL PROCEDURES}

\section{EPM Test}

Male ICR:CD-1 mice (Harlan, Indianapolis, IN) were 5 weeks old at the time of testing. The EPM (HamiltonKinder, Poway, CA) was constructed from black Plexiglas based on a design validated by Lister (1987). The maze consisted of two open arms $(37.5 \times 5 \times 0.3 \mathrm{~cm})$ and two closed arms $(37.5 \times 5 \times 15 \mathrm{~cm})$, which extended from the central platform $(5 \times 5 \mathrm{~cm})$. The maze was elevated $63 \mathrm{~cm}$ above the floor. Light beam breaks were recorded and analyzed automatically using Motor Monitor software (Hamilton-Kinder, Poway, CA). A modified zone map was used. The central area was extended to include the first $2.5 \mathrm{~cm}$ of each arm, thus the arm area was defined as the most distal $(35 \mathrm{~cm})$. An arm entry was recorded when the center of the mouse entered the distal part of the arm. This corresponds to the definition of the arm entry as all four legs on the arm (Lister, 1987). Data were expressed as the time spent in open arms as a percent of total testing time, and as the number of open arm entries. The total amount of ambulations was used to determine the locomotor activity of tested mice.

Testing was performed between 0900 and 1200. On the test day, animals were transferred to the testing room in their home cages and allowed to acclimate for at least $1 \mathrm{~h}$ prior to saline or LY354740 $(20 \mathrm{mg} / \mathrm{kg}$, s.c.) injections. Immediately after injections, animals were placed in individual holding cages until tested $30 \mathrm{~min}$ later. A test session began by placing a mouse on the central platform facing the open arm to allow free exploration of the maze for $5 \mathrm{~min}$. After testing, the mouse was returned to its holding cage and the maze was cleaned with methanol. Animals remained in the testing room until the brains were collected $2 \mathrm{~h}$ after EPM exposure. Control (no EPM) animals were injected with saline or LY354740 and placed in individual holding cages until they were killed $2.5 \mathrm{~h}$ later. The time point was based on our preliminary experiments and previous studies showing prominent c-Fos induction $2 \mathrm{~h}$ after pharmacological treatments or stress exposures (Graeff et al, 1993; Stone and Zhang, 1995; Duncan et al, 1996; Ryabinin et al, 1997). Mice were anesthetized (5\% isoflurane) and decapitated. Brains were rapidly removed, frozen in isopentane over dry ice, and stored at $-80^{\circ} \mathrm{C}$ until sectioning. The animal protocols were approved by Lilly Research Laboratories Animal Care and Use Committee and were in accordance with the National Institute of Health Guide for the Care and Use of Laboratory Animals (NIH Publications No. 80-23, revised 1996). 


\section{c-Fos Immunohistochemistry}

Coronal brain sections $(14 \mu \mathrm{m})$ were cut with a cryostat, thaw-mounted on Super Frost/Plus slides (Menzel-Glaeser, Germany), and stored at $-20^{\circ} \mathrm{C}$. c-Fos expression was analyzed in the selected brain regions shown in Figure 1. Slides were removed from the freezer, allowed to air-dry for $15 \mathrm{~min}$, and fixed for $10 \mathrm{~min}$ in ice-cold $4 \%$ paraformaldehyde in phosphate-buffered saline ( $\mathrm{pH}$ 7.4, PBS). After several washes in PBS containing $0.05 \%$ Tween 20 (PBST20), the sections were treated in $0.3 \%$ hydrogen peroxide in methanol for $15 \mathrm{~min}$ to block endogenous peroxidases. The sections were incubated for $20 \mathrm{~min}$ in blocking buffer containing $5 \%$ horse normal serum and $1 \%$ fatty acid free bovine serum albumin (BSA) in PBST20. After removal of the blocking buffer, incubation buffer (1\% BSA in PBST20) containing goat polyclonal anti-c-Fos antibody ( $1: 1000$, SC-52G, Santa Cruz Biotechnology, Santa Cruz, CA) was applied overnight at $4^{\circ} \mathrm{C}$. Negative control sections were incubated without primary antibody. After

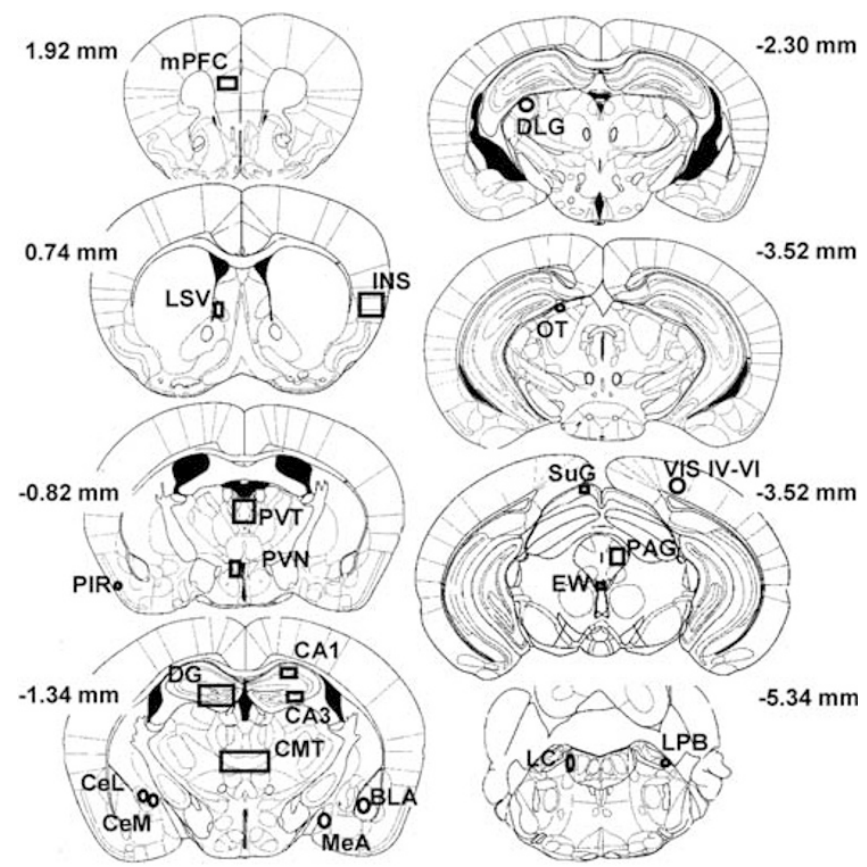

Figure I Schematic diagrams of brain sections adapted from the mouse brain atlas (Franklin and Paxinos, 1997) represent the approximate anteroposterior levels (to Bregma) where select brain regions were analyzed. The location and size of the analyzed area for each region is indicated. BLA, basolateral nucleus of the amygdala $\left(0.12 \mathrm{~mm}^{2}\right)$; CAI, CAI pyramidal cell layer of the hippocampus $\left(0.1 \mathrm{~mm}^{2}\right)$; CA3, CA3 pyramidal cell layer of the hippocampus $\left(0.1 \mathrm{~mm}^{2}\right)$; CeL, lateral division of the central nucleus of the amygdala $\left(0.07 \mathrm{~mm}^{2}\right)$; CeM, medial division of the central nucleus of the amygdala $\left(0.10 \mathrm{~mm}^{2}\right)$; CMT, centromedial nucleus of thalamus $\left(0.28 \mathrm{~mm}^{2}\right)$; DG, granular cell layer of the dentate gyrus $\left(0.5 \mathrm{~mm}^{2}\right)$; DLG, dorsal lateral geniculate nucleus of the thalamus $\left(0.10 \mathrm{~mm}^{2}\right)$; EW, Edinger-Westphal nucleus $\left(0.03 \mathrm{~mm}^{2}\right)$; INS, insular cortex $\left(0.30 \mathrm{~mm}^{2}\right)$; LC, locus coeruleus $\left(0.04 \mathrm{~mm}^{2}\right)$; LPB, lateral parabrachial nucleus $\left(0.03 \mathrm{~mm}^{2}\right)$; LSV, lateral septum ventral part $\left(0.08 \mathrm{~mm}^{2}\right)$; MeA, medial nucleus of the amgydala $\left(0.12 \mathrm{~mm}^{2}\right)$; $\mathrm{mPFC}$, medial prefrontal cortex $\left(0.16 \mathrm{~mm}^{2}\right)$; OT, nucleus of the optic tract $\left(0.04 \mathrm{~mm}^{2}\right)$; PAG, lateral periaqueductal gray $\left(0.12 \mathrm{~mm}^{2}\right)$; $\mathrm{PIR}$, piriform cortex $\left(0.04 \mathrm{~mm}^{2}\right)$; PVN, paraventricular nucleus of the hypothalamus $\left(0.10 \mathrm{~mm}^{2}\right)$; PVT, paraventricular nucleus of the thalamus $\left(0.25 \mathrm{~mm}^{2}\right)$; SuG, superficial gray layer of the superior colliculus $\left(0.03 \mathrm{~mm}^{2}\right)$; VIS IV-VI, primary visual cortex, layers IV-VI $\left(0.10 \mathrm{~mm}^{2}\right)$. washes with PBST20, slides were incubated with a biotinylated horse anti-goat IgG $(1: 200$; Vector Laboratories, Burlingame, CA) in incubation buffer for $1 \mathrm{~h}$ followed by incubation with an avidin-horseradish peroxidase solution for $1 \mathrm{~h}$ (Vectastain Elite $\mathrm{ABC}$, Vector). After washes in PBST20, visualization of bound peroxidase complexes was performed by incubating sections in a chromogen solution containing diaminobenzidine and nickel sulfate intensification (DAB Substrate kit, Vector) for $8 \mathrm{~min}$. The reaction was stopped by PBST20. The sections were dehydrated and coverslipped with Permount (Fisher Chemicals, Fair Lawn, NJ). No c-Fos signal was observed in negative control sections.

\section{Quantification of c-Fos Immunoreactive Cells}

The capture of microscopic images and cell count was performed blind to the treatment. Photomicrographs from anatomically matched sections were captured using a Spot RT digital color camera (Diagnostic Instruments, Sterling Heights, MI) under a light microscope (Leica DMR, Leica Microsystems, Wetzlar, Germany). Image Pro Plus digitizing software (Media Cybernetics, Silver Spring, ML) was used to set thresholds and count c-Fos positive cells. For select brain regions, c-Fos positive cells were counted bilaterally from two sections spaced $84 \mu \mathrm{m}$ apart from each animal. The bilateral counts from two sections were averaged to obtain a single value for each animal. The number of c-Fos positive cells in the indicated area of brain tissue represents the mean \pm SEM of 8-12 animals per treatment group. The size of the analyzed brain areas and their approximate antero-posterior levels (relative to Bregma) are shown in Figure 1.

\section{Statistical Analysis}

The behavioral data were analyzed using Student's $t$-test. $c$-Fos data were analyzed by two-way analysis of variance (ANOVA), with $p<0.05$ considered as being statistically significant. Post hoc analysis was performed using Tukey's Multiple Comparison Test.

\section{RESULTS}

\section{Effect of LY354740 $(20 \mathrm{mg} / \mathrm{kg}$, s.c.) on EPM Behavior}

LY354740 (20 mg/kg, s.c.) administered $30 \mathrm{~min}$ prior to the EPM test significantly increased anxiolytic-like behavior in the outbred ICR:CD-1 strain of mice, which is consistent with previous reports using other mouse strains (Monn et al, 1997; Helton et al, 1998). LY354740-treated mice spent significantly more time in the open arms and entered the open arms more frequently than saline-treated mice (Figure $2 a$ and b). LY354740 had no effect on closed arm time (Figure 2c), and the total number of ambulations (locomotor activity) was not significantly different between saline and LY354740 treatments (Figure 2d).

\section{Suppression of EPM-Induced c-Fos Expression in the Hippocampus by Systemic LY354740}

Two-way ANOVA revealed a significant effect of the treatment (no EPM vs EPM) on the number of c-Fos 

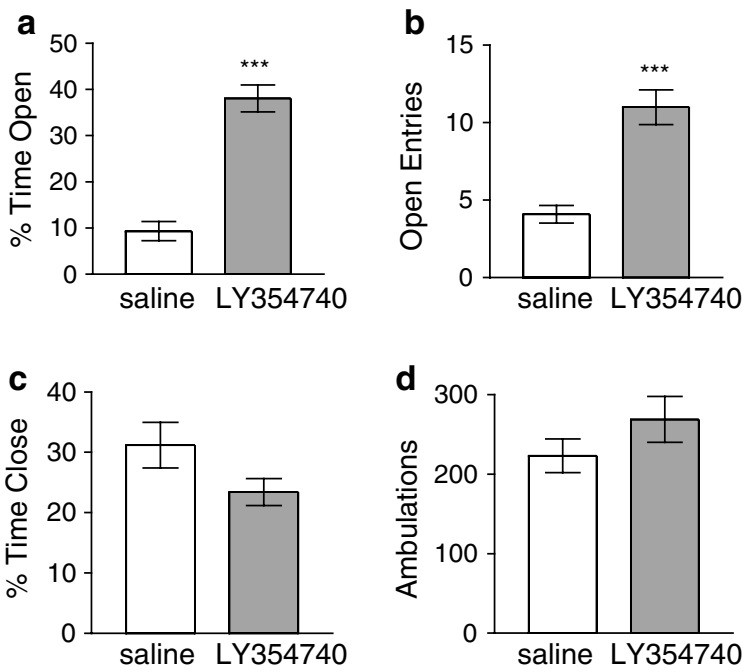

Figure 2 Effect of systemic LY354740 on the EPM behavior under low light conditions. Male ICR:CD-I mice were injected with saline or LY354740 (20 mg/kg, s.c.) $30 \mathrm{~min}$ prior to testing on the EPM for $5 \mathrm{~min}$. Time spent in open arms as a percent of total testing time (a), the number of entries into open arms (b), time spent in closed arms as a percent of total testing time (c), and the counts of total ambulations (d) are shown as the mean \pm SEM of 12 animals. Significant difference between treatment groups: ${ }^{* * * *} p<0.001$, Student's t-test.

positive cells in the pyramidal cell layer of the hippocampal CA3 $(p<0.001)$, and the granular layer of the dentate gyrus (DG) $(p<0.05)$. The results also showed a significant effect of LY354740 administration in all three (CA3, $p<0.05$; CA1, $p<0.01$; and DG, $p<0.01$ ) hippocampal subregions studied. In the CA3, there was also a significant interaction between these two factors $(p<0.05)$. Post hoc analysis confirmed that the number of c-Fos positive cells was significantly increased in the CA3 subregion $2 \mathrm{~h}$ after the EPM exposure (Figures $3 \mathrm{a}$ and $4 \mathrm{~b}$ ). This EPM-induced c-Fos increase was suppressed by pretreatment with LY354740 $(20 \mathrm{mg} / \mathrm{kg}$, s.c.) back to the basal level (Figures $3 \mathrm{a}$ and $4 \mathrm{~d}$ ). In the CA1 and DG, the numbers of c-Fos positive cells were significantly lower in LY354740-treated mice compared to the saline-treated and EPM-exposed groups of animals (Figures $3 b$ and c). LY354740 administration did not affect the number of c-Fos positive cells in control mice (no EPM) compared with saline-treated control mice (Figures $3 \mathrm{a}-\mathrm{c}$ and $4 \mathrm{a}$ and $\mathrm{c}$ ).

\section{c-Fos Induction in the Amygdala by Systemic LY354740}

The EPM exposure had no significant effect (two-way ANOVA) on c-Fos expression in any of the amygdaloid nuclei studied (Figure 5). Two-way ANOVA revealed that LY354740 (20 mg/kg, s.c.) treatment produced significant effects in the lateral division of the central nucleus of the amygdala (CeL, $p<0.0001)$, medial division of the central nucleus of the amygdala (CeM, $p<0.001)$, and basolateral nucleus of the amygdala (BLA, $p<0.05$, Figure $5 c$ ). Post hoc analysis confirmed that LY354740 administration significantly increased the number of c-Fos positive cells in the CeL (Figures $5 \mathrm{a}$ and $6 \mathrm{c}$ and $\mathrm{d}$ ). An increased number of scattered c-Fos positive cells were also found in the CeM after LY354740 administration (Figure 5b). LY354740-
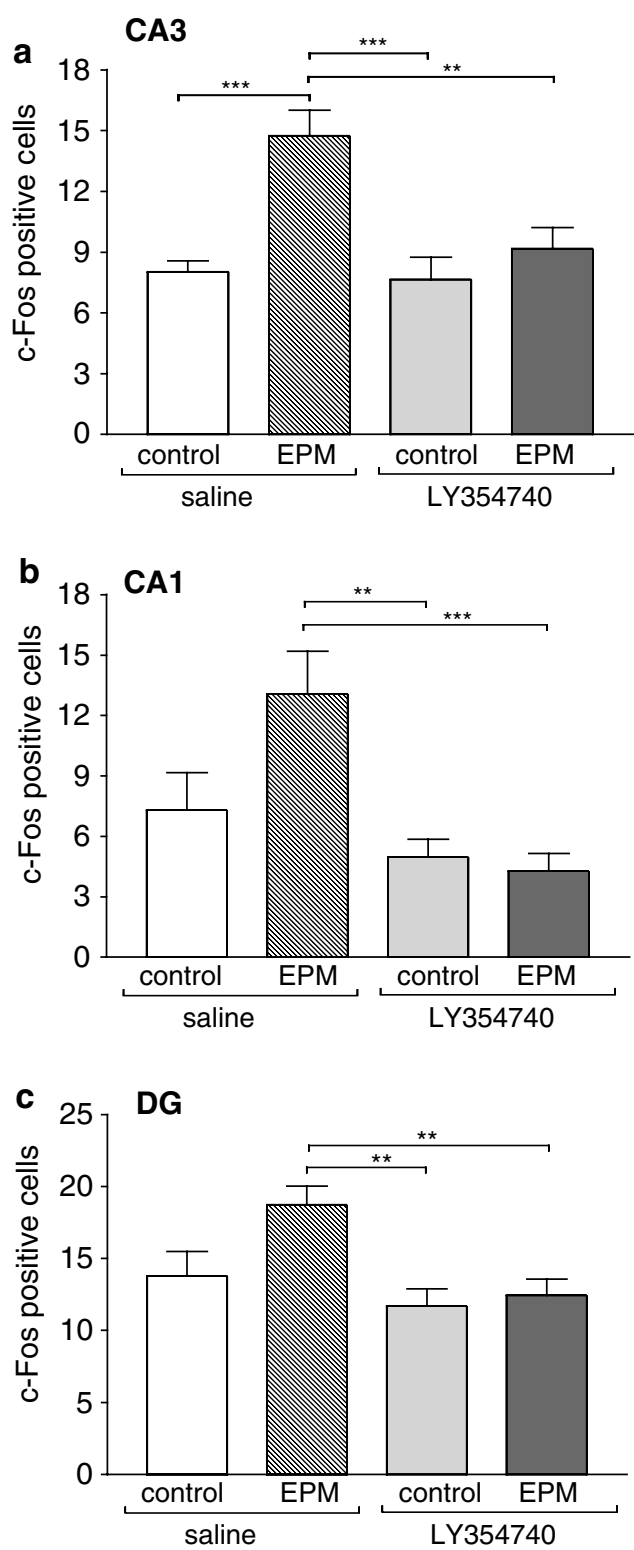

Figure 3 Effect of LY354740 (20 mg/ $/ \mathrm{kg}$, s.c.) on the number of c-Fos positive cells in the CA3 (a), CAI (b), and DG (c) subregions of the hippocampus in control (no EPM) and EPM-tested mice. EPM-tested mice were injected with saline or LY354740 (20 mg/kg, s.c.), kept in individual holding cages for $30 \mathrm{~min}$, tested on the EPM for $5 \mathrm{~min}$, and returned to the holding cages until they were killed $2 \mathrm{~h} 30 \mathrm{~min}$ after injections. Control mice were injected with saline or LY354740 (20 mg/ $/ \mathrm{kg}$, s.c.) and kept in the individual holding cages for $2 \mathrm{~h} 30$ min until they were killed. Data represent the mean \pm SEM of the number of c-Fos positive cells in an indicated brain region $(n=8-12)$. The location, size, and abbreviation of the analyzed areas are indicated in Figure I; $*^{*} * * 00.001,{ }^{*} * p<0.01$, ${ }^{*} p<0.05$, two-way ANOVA followed by Tukey's Multiple Comparison Test.

induced c-Fos expression was more pronounced in the posterior than in the anterior portions of the CeL (data not shown). The effect of LY354740 in the CeL was observed both in control (no EPM) and in EPM-treated mice (Figures $5 \mathrm{a}$ and $6 \mathrm{c}$ and d). Since the dorsolateral bed nucleus of the stria terminalis (BNST) has been shown to have a c-Fos induction profile similar to the CeL (Compaan et al, 1996; Ryabinin et al, 1997; Hitzemann and Hitzemann, 1999), we performed a separate experiment to analyze the number of 


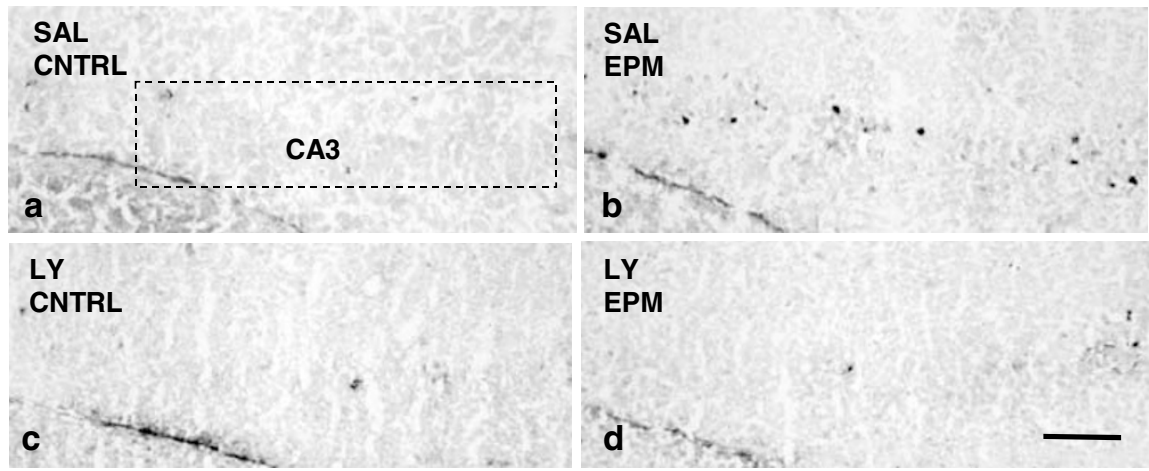

Figure 4 LY354740 (20 mg/kg, s.c.) suppressed the EPM-induced c-Fos expression in the CA3 pyramidal cell layer of the hippocampus. Representative photomicrographs of c-Fos immunoreactivity on $14 \mu \mathrm{m}$ coronal brain sections of saline-treated control (a), saline-treated EPM-exposed (b), LY354740treated control (c), and LY354740-treated EPM-exposed (d) mice. Animal treatments are as described in Figure 3. The dotted line delineates the CA3 area quantified in Figure 3. Scale bar $=100 \mu \mathrm{m}$.

c-Fos positive cells in this region after saline and LY354740 $(20 \mathrm{mg} / \mathrm{kg}$, i.p.) administration. c-Fos expression was found to be significantly increased by systemic LY354740 compared to saline treatment $(23.5 \pm 4.2$ vs $4.4 \pm 1.5$ c-Fos positive cells, $p<0.001$, Student's $t$-test, $n=8$ ).

\section{c-Fos Induction in other Stress-Related Brain Regions by Systemic LY354740}

Several other stress-related brain regions (Figure 1) were analyzed to determine if EPM exposure or LY 354740 administration affects c-Fos expression outside the hippocampus and amygdala. These regions include the mPFC, insular cortex (INS), piriform cortex (PIR), lateral septum ventral part (LSV), paraventricular nucleus of the thalamus (PVT), centromedial nucleus of the thalamus (CMT), paraventricular nucleus of the hypothalamus (PVN), lateral periaqueductal gray (PAG), Edinger-Westphal nucleus (EW), lateral parabrachial nucleus (LPB), and locus coeruleus (LC). c-Fos expression was not significantly affected by the EPM exposure in any of these regions (Figure 7).

In cortical regions, c-Fos expression was not significantly affected by LY354740 $(20 \mathrm{mg} / \mathrm{kg}$, s.c. $)$ administration (Figure 7a-c). Two-way ANOVA revealed that LY354740 treatment had significant effects in specific subcortical structures, including the PVT $(p<0.0001)$, CMT $(p<0.01)$, PVN $(p<0.05)$, and EW $(p<0.0001)$, as well as brainstem structures LPB $(p<0.0001)$ and LC $(p<0.001)$. Post hoc analysis for each region confirmed a significant induction of c-Fos expression by LY354740 both in control (no EPM) and EPM-treated mice in PVT (Figure 7e), EW (Figure 7i), LPB (Figure 7j), and LC (Figure 7k). In the thalamus, the induction of c-Fos by LY354740 was found not only in the PVT but also in the dorsolateral geniculate nucleus of the thalamus (DLG, see below). A regionally restricted group of c-Fos positive cells was detected in the EW after LY354740 administration (Figure 8b). In the LPB, c-Fos induction by LY354740 was most pronounced in the external areas, where quantitative analysis was performed (Figure 7j). However, c-Fos levels were also increased in other areas of the LPB (data not shown). In the LC, LY354740 administration produced a pronounced increase of c-Fos immunoreactive cells as shown in Figure 9.

\section{c-Fos Induction in Central Visual Regions by Systemic 1Y354740}

Two-way ANOVA revealed that LY354740 administration $(20 \mathrm{mg} / \mathrm{kg}$, s.c.) had significant effects in regions of the central visual system, including the DLG $(p<0.0001)$, nucleus of the optic tract (OT, $p<0.0001$ ), and superficial gray layer of the superior colliculus (SuG, $p<0.0001)$. Post hoc analysis for each region confirmed a significant induction of c-Fos expression after LY354740 administration in all three regions in both control (no EPM) and EPMtreated mice (Figure 10). c-Fos induction in the superior colliculus was highly specific to the SuG compared to its other layers (Figure 11f). No significant change was observed in the primary visual cortex layers IV-VI (VIS IV-VI; Figure 10d). In addition to the strong induction by LY354740 in the OT (Figure 10b and 11d), an increased number of c-Fos positive cells after LY354740 administration was observed in the other pretectal nucleus called the medial terminal nucleus of the accessory OT (data not shown). As mentioned above, LY354740 administration increased c-Fos expression in the EW (Figure 7i and 8), an oculomotor nucleus receiving projections from the pretectal nuclei. The EW has recently been implicated in the regulation of stress/anxiety via its urocortin-containing neurons (Vaughan et al, 1995; Kozicz et al, 1998; Weninger et al, 1999, 2000; Skelton et al, 2000; Kozicz, 2003), and was therefore grouped in the present study with the other stressrelated brain regions (Figure 7).

\section{DISCUSSION}

Pretreatment with LY354740 increased anxiolytic-like behaviors of mice on the EPM. This behavioral effect was accompanied by the blockade of EPM-induced c-Fos expression in the hippocampus. In several other brain regions, LY354740 administration alone increased neuronal activation. c-Fos expression was induced by LY354740 in stress-related brain regions such as the amygdala, EW, and LC, and also in the thalamic and midbrain structures that process sensory information. It has been shown that systemically administered LY354740 reaches the brain at pharmacologically relevant concentrations (see Schoepp et al, 2003). However, we cannot rule out the possibility that 

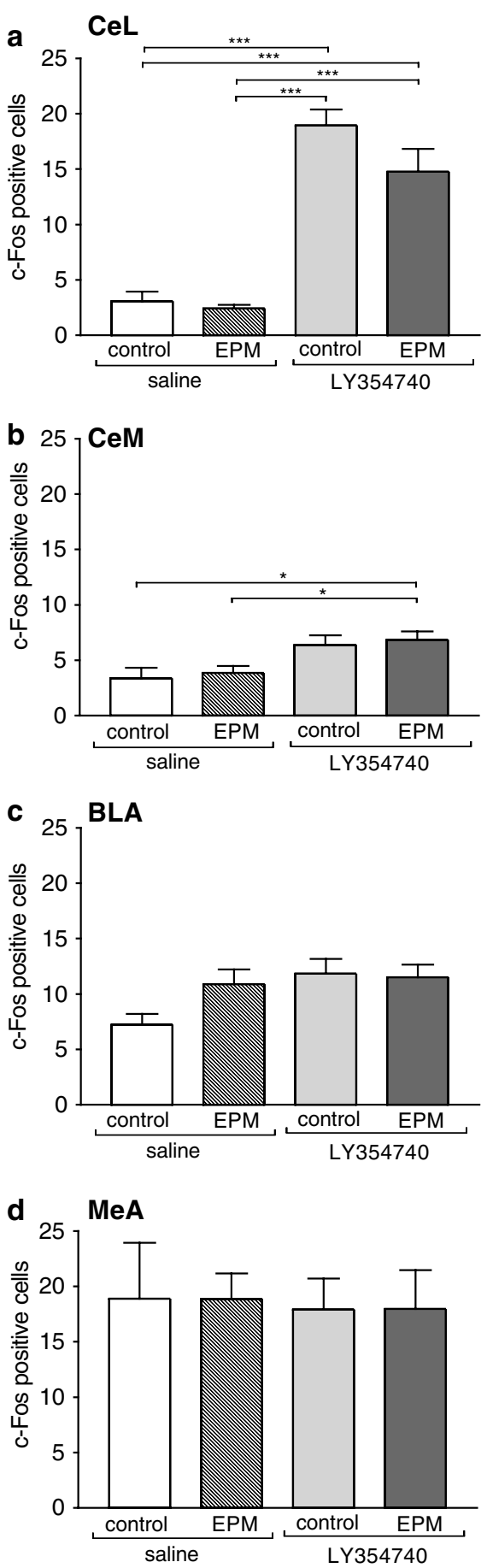

Figure 5 Effect of LY354740 (20 mg/kg, s.c.) on the number of c-Fos positive cells in the CeL (a), CeM (b), BLA (c), and MeA (d) in control (no EPM) and EPM-tested mice. Animal treatments are as described in Figure 3. Data represent the mean \pm SEM of the number of c-Fos positive cells in an indicated brain region $(n=8-12)$. The location, size, and abbreviation of the analyzed areas are indicated in Figure I; $* * * * 0<0.001$, ${ }^{* *} p<0.01, * p<0.05$, two-way ANOVA followed by Tukey's Multiple Comparison Test.

c-Fos induction in some brain regions is due to some as of yet undefined non-CNS effects of LY354740.

In the present study, EPM exposure increased c-Fos expression significantly in the CA3 subregion of the hippocampus, but not in other limbic brain regions. This is in contrast to the previous reports of EPM-induced c-Fos expression in several limbic brain regions (Graeff et al, 1993; Duncan et al, 1996; Hinks et al, 1996). These discrepancies may be due to longer EPM exposure times (15-30 min) along with control animals that were kept undisturbed in their home cages (Graeff et al, 1993; Duncan et al, 1996; Hinks et al, 1996). In the present study, a 5-min exposure time and dim lighting conditions reduced the stressfulness of EPM exposure. In addition, the control animals (no EPM) were injected with saline and placed in a novel cage; thus c-Fos induction caused by handling, injections (s.c.), and a novel environment probably prevented significant differences in c-Fos expression from occurring between control and EPM-exposed animals.

Exposure to EPM increased c-Fos expression in the hippocampus. This is consistent with the reports of increased activity in the hippocampus after various stress/ fear stimuli (Beck and Fibiger, 1995; Stone and Zhang, 1995; Chowdhury et al, 2000). The suppression of stress-induced neuronal activity in the hippocampus by LY354740 suggests that its anxiolytic effects may be mediated by its actions on hippocampal neurotransmission. A recent report demonstrating that the intrahippocampal administration of LY354740 produced anticonflict effect in rat Vogel drinking test (Tatarczynska et al, 2001) further supports the model where the reduction of stress-induced activity in the hippocampus is associated with the anxiolytic action of LY354740. It has been shown that anxiolytic doses of diazepam suppress stress-induced c-Fos expression in the DG and CA1 hippocampal regions (Beck and Fibiger, 1995) and high doses of chlordiazepoxide also decrease basal c-Fos expression in the CA1 (Hitzemann and Hitzemann, 1999). Similarly, systemic administration of ethanol reduces not only novelty-induced but also basal c-Fos expression in the hippocampus (Ryabinin et al, 1997). However, under the conditions of this study, LY354740 did not affect the basal c-Fos expression in the hippocampus.

Several studies demonstrate that mGlu2/3 receptor agonists, including LY354740, reduce excitatory postsynaptic potentials (EPSPs) via presynaptic mechanisms in the terminal fields of the medial perforant path in the DG midmolecular layer and CA1 stratum lacunosum moleculare (Kilbride et al, 1998, 2001; Kew et al, 2002). mGlu2 receptors at mossy fiber-CA3 synapses function as the inhibitory autoreceptors that are activated only after excessive stimulation (Scanziani et al, 1997). This may help to explain why LY354740 suppressed only EPM-induced, but not basal neuronal activity in the CA3 pyramidal cell layer. Moreover, electrophysiological recordings on hippocampal slices from mGlu2 receptor knockout mice demonstrated that mGlu2 receptors are not required for the basal synaptic transmission at the mossy fiber-CA3 synapse (Yokoi et al, 1996).

Intra-amygdaloid circuitry processes adversive information and regulates behavioral, autonomic, and neuroendocrine responses to stress/fear stimuli through the central nucleus, the main output region of the amygdala (Sun and Cassell, 1993; Davis et al, 1994; Pitkanen et al, 1997). Here, we show that systemic administration of LY354740 increased neuronal activity in the CeL and dorsolateral BNST. This effect of LY354740 may be mediated locally or via neuronal pathways projecting to the amygdala. Local 


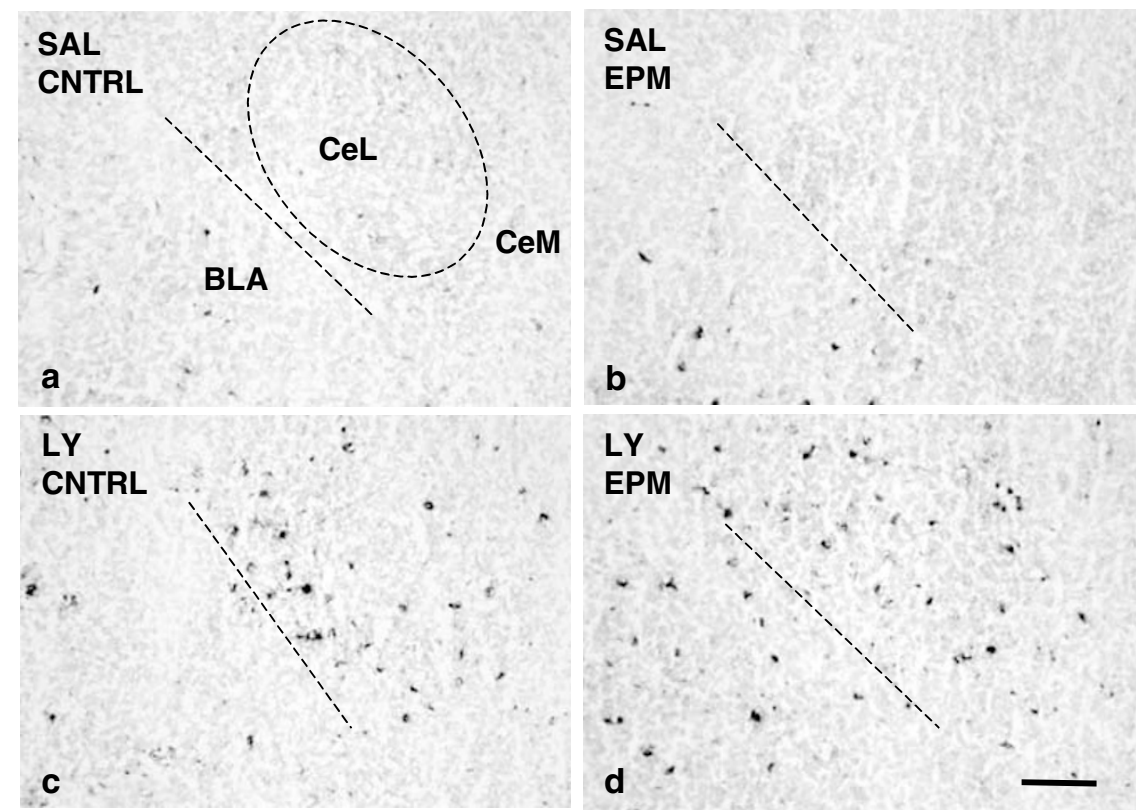

Figure $6 \mathrm{LY} 354740(20 \mathrm{mg} / \mathrm{kg}$, s.c.) induced c-Fos expression in the CeL in control and EPM-tested mice. Representative photomicrographs of c-Fos immunoreactivity on $14 \mu \mathrm{m}$ coronal brain sections of saline-treated control (a), saline-treated EPM-exposed (b), LY354740-treated control (c), and LY354740-treated EPM-exposed (d) mice. Animal treatments are as described in Figure 3. The circle indicates the CeL area quantified in Figure 5. Note that only a part of the CeM is shown. The dotted line delineates the border of the BLA. Scale bar $=100 \mu \mathrm{m}$.

actions of LY354740 in the amygdala are supported by the study demonstrating that LY354740 can suppress excitatory postsynaptic currents in the central nucleus evoked by stimulation of the BLA (Neugebauer et al, 2000). However, this suppressive effect of locally applied LY354740 does not help to explain why systemic LY354740 increased neuronal activity in the CeL in our study. Nevertheless, a role for local amygdaloid circuitry in the actions of LY354740 in suppressing fear-potentiated startles has recently been demonstrated following intra-amygdaloid (into the lateral amygdala) injections (Walker et al, 2002). Alternatively, two brain regions projecting heavily to the CeL, the PVT, and LPB (Krukoff et al, 1993; Moga et al, 1995; Veinante and Freund-Mercier, 1998) were activated by systemic LY354740, suggesting a mechanism mediated via these structures.

Based on neuroanatomical and electrophysiological characterization of neuronal circuitries within the central nucleus of amygdala, it has been suggested that inhibitory neurons in the CeL provide a strong and tonic inhibition over output neurons in the CeM (Sun and Cassell, 1993; Sun et al, 1994; Veinante and Freund-Mercier, 1998). This model suggests that fear/stress alters the activity of CeL neurons leading to reduced inhibition (disinhibition) of CeM output neurons that target regions regulating stress/fear responses. Neuronal activity in the CeL is increased by several anxiolytic compounds, including benzodiazepines and ethanol (Beck and Fibiger, 1995; Salminen et al, 1996; Ryabinin et al, 1997; Hitzemann and Hitzemann, 1999). These activated neurons in CeL (and scattered c-Fos positive neurons in $\mathrm{CeM}$ ) have been shown to be GABAergic inhibitory neurons (Hitzemann and Hitzemann, 1999). Thus, increased activity of GABAergic neurons in $\mathrm{CeL}$ induced by anxiolytic compounds could enhance the inhibitory tone and therefore restore the inhibition of the
CeM output that was reduced by stress/fear. Since LY 354740 produced a c-Fos induction pattern in the amygdala similar to benzodiazepines, a similar mechanism could underlie the anxiolytic actions of LY354740. Furthermore, this model of reduced inhibitory tone is supported by an observation that amphetamine-induced c-Fos expression in the inhibitory neurons of the CeL was significantly greater in the home compared to the novel environment, suggesting that the activity of GABAergic neurons is indeed suppressed by a more stressful environment (Day et al, 2001). Further studies are needed to compare the level of c-Fos induction by LY35470 in the home $v s$ a more aversive environment and to identify the neuronal populations activated by LY354740.

In addition to anxiolytic agents, c-Fos expression is induced in the CeL by different types of pharmacological agents, including anxiogenic compounds (Bittencourt and Sawchenko, 2000; Singewald and Sharp, 2000; Day et al, 2001), severe stress (Chowdhury et al, 2000), and peripheral autonomic challenges (McKitrick et al, 1992; Sagar et al, 1995). Clearly, c-Fos induction in the CeL is not specific for anxiolytic agents. However, it is possible that different types of stimuli (eg anxiolytic and anxiogenic) could activate different neuronal populations in that region. Although the activation of the CeL may not per se mediate the actions of anxiolytic agents, it may be important in executing their actions by mediating neuroendocrine, autonomic, and behavioral responses initiated in other limbic brain regions. Similarly, it appears that the same factors that induce c-Fos in CeL also induce c-Fos in LPB. The simultaneous activation of these two brain regions may be due to their interconnections.

The PVN is another region where various anxiogenic stimuli (Beck and Fibiger, 1995; Stone and Zhang, 1995; Bittencourt and Sawchenko, 2000), and also anxiolytic 

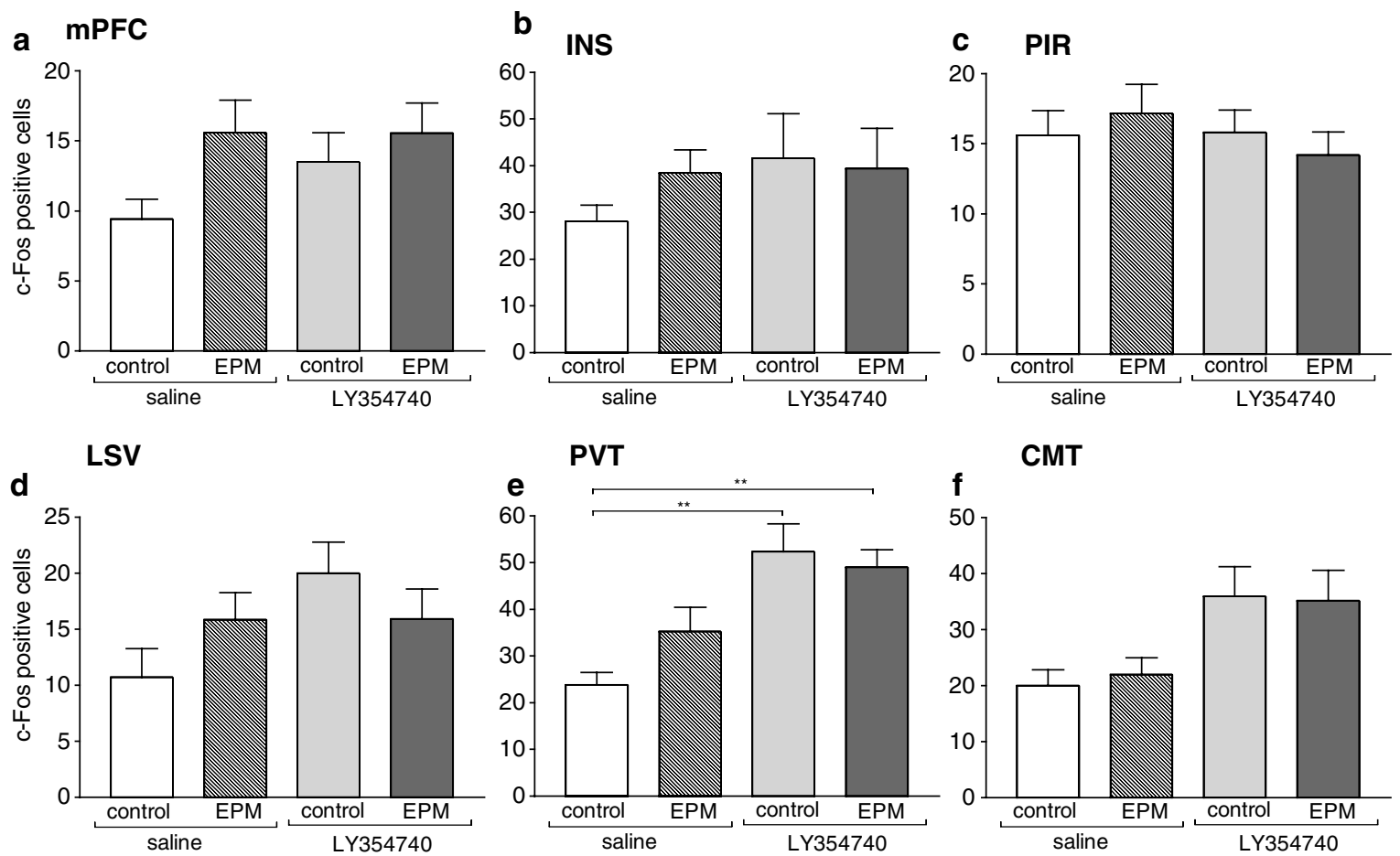

\section{PVN}

g
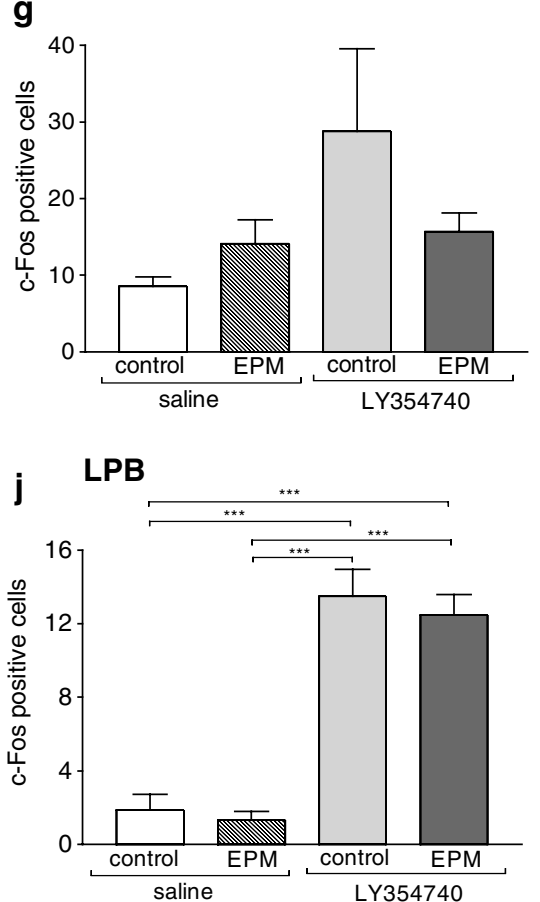

PAG
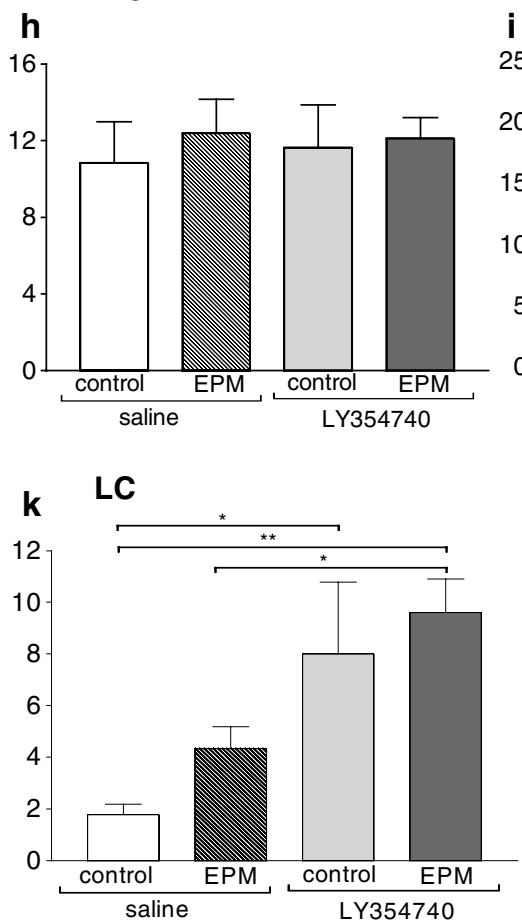

EW

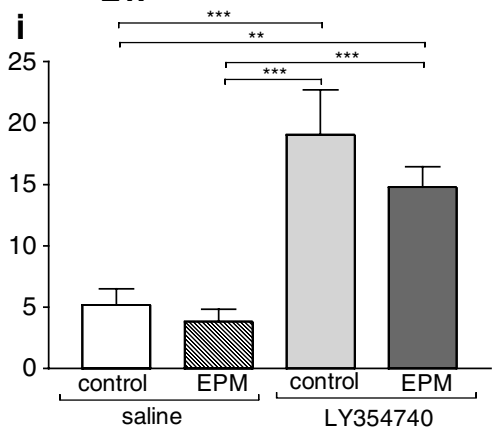

Figure 7 Effect of LY354740 (20 mg/kg, s.c.) on the number of c-Fos positive cells in mPFC (a), INS (b), PIR (c), LSV (d), PVT (e), CMT (f), PVN (g), PAG (h), EW (i), LPB (j), and LC (k). Animal treatments are as described in Figure 3. Data represent the mean \pm SEM of the number of c-Fos positive cells in an indicated brain region $(n=8-12)$. The location, size, and abbreviation of the analyzed areas are indicated in Figure I. $* * * * p<0.001$, $* * p<0.01$, $* p<0.05$, twoway ANOVA followed by Tukey's Multiple Comparison Test.

agents such as diazepam (Salminen et al, 1996), flesinoxan $\left(5-\mathrm{HT}_{1 \mathrm{~A}}\right.$ agonist; Compaan et al, 1996) and ethanol (Ryabinin et al, 1997) induce c-Fos expression. However, in the present study, systemic LY354740 did not significantly increase c-Fos expression in the PVN. Consistent with these findings, Johnson et al (2001) have shown that
LY354740 $(10 \mathrm{mg} / \mathrm{kg}$, i.p. $1 \mathrm{~h})$ did not significantly alter blood corticosterone levels in rats.

The EW was one of the brain regions clearly activated by systemic LY354740. This oculomotor nucleus regulates pupillary reflexes and contains preganglionic parasympathetic neurons that innervate ciliary postganglionic neurons 


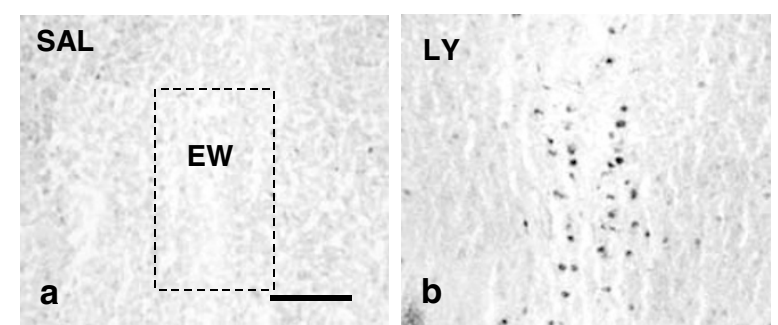

Figure 8 LY354740 (20 mg/kg, s.c.) induced c-Fos expression in the EW Representative photomicrographs of c-Fos immunoreactivity on $14 \mu \mathrm{m}$ coronal brain sections of saline-treated (a) and LY354740-treated (b) control mice (no EPM). Animal treatments are as described in Figure 3. The dotted line delineates the EW area quantified in Figure 7. Scale bar $=100 \mu \mathrm{m}$.

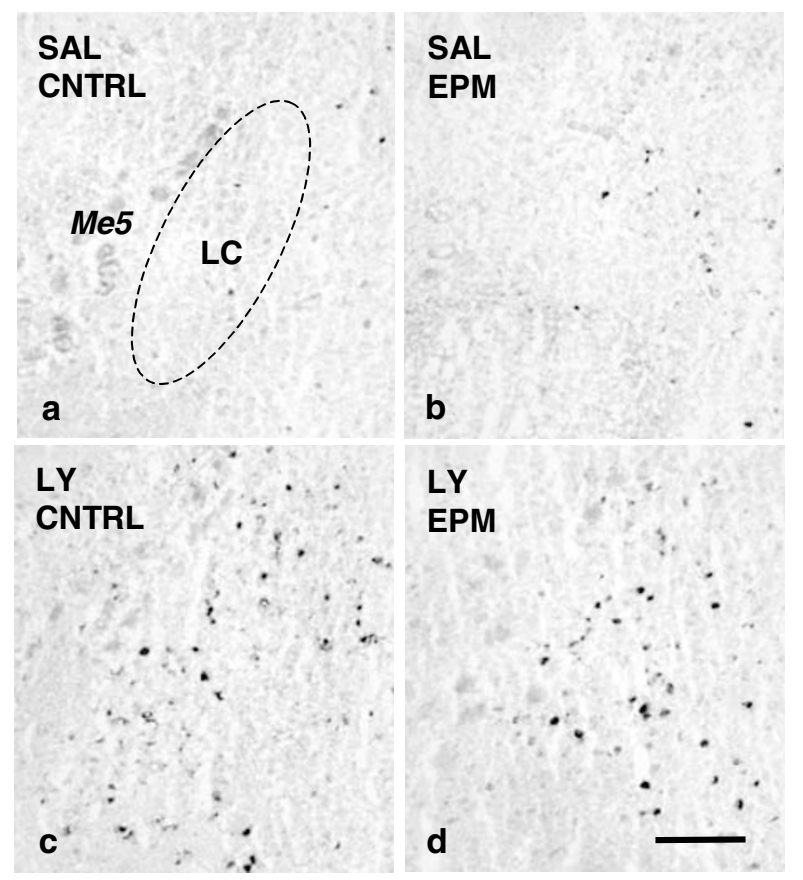

Figure 9 LY354740 (20 mg/kg, s.c.) induced c-Fos expression in the LC in control and EPM-tested mice. Representative photomicrographs of c-Fos immunoreactivity on $14 \mu \mathrm{m}$ coronal brain sections of saline-treated control (a), saline-treated EPM-exposed (b), LY354740-treated control (c), and LY354740-treated EPM-exposed (d) mice. Animal treatments are as described in Figure 3. The dotted line delineates the LC area quantified in Figure 7. Scale bar $=100 \mu \mathrm{m}$. Me5, mesencephalic 5 nucleus.

(see Trimarchi, 1992; Klooster et al, 1993). Besides oculomotor functions, recent reports suggest the involvement of the EW in stress responses, anxiolytic actions of chronic benzodiazepine administration, and alcohol consumption (Skelton et al, 2000; Weninger et al, 2000; Bachtell et al, 2003; Kozicz, 2003). The EW is the primary source of the novel corticotropin-related neuropeptide urocortin in the rat and mouse brain (Vaughan et al, 1995; Kozicz et al, 1998; Weninger et al, 1999). The functional role of urocortin pathway and activation of EW neurons is currently under intense investigation. Our results suggest a role for the EWurocortin pathway in the anxiolytic effects of LY354740. The role of glutamate neurotransmission in the regulation of neuronal activity in the EW is supported by the observation
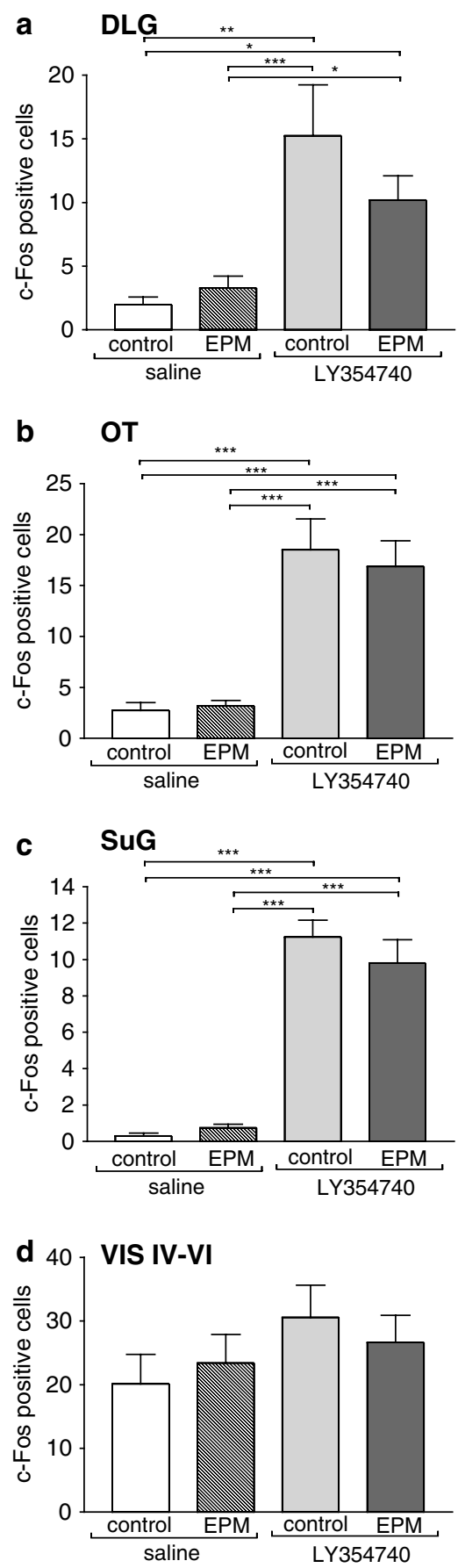

Figure 10 Effect of $L Y 354740(20 \mathrm{mg} / \mathrm{kg}$, s.c.) on the number of c-Fos positive cells in the central visual regions, including DLG (a), OT (b), SuG (c), and $\mathrm{VIS} \mathrm{IV-VI} \mathrm{(d).} \mathrm{Animal} \mathrm{treatments} \mathrm{are} \mathrm{as} \mathrm{described} \mathrm{in} \mathrm{Figure} \mathrm{3.} \mathrm{Data}$ represent the mean \pm SEM of the number of c-Fos positive cells in an indicated brain region $(n=8-12)$. The location, size, and abbreviation of the analyzed areas are indicated in Figure I. ***** $p<0.00$ I, *** $p<0.01$, ${ }^{*} p<0.05$, two-way ANOVA followed by Tukey's Multiple Comparison Test.

that ionotropic glutamate receptor antagonists such as ketamine also induced c-Fos in the EW (Craner et al, 1992).

Systemic LY354740 increased c-Fos expression in several central visual regions, including DLG, OT, and SuG. This effect is not specific for mGlu2/3 receptor agonists since systemic nicotine induces c-Fos expression in the same 


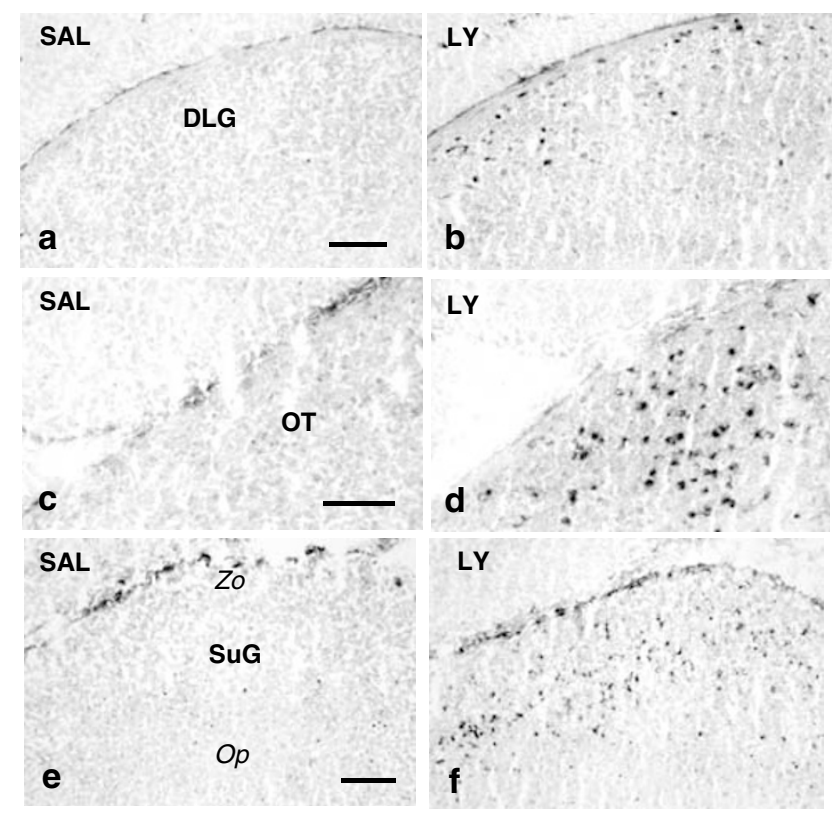

Figure I I LY354740 (20 mg/kg, s.c.) induced c-Fos expression in the DLG (b), OT (d), and SuG (f). Representative photomicrographs of c-Fos immunoreactivity on $14 \mu \mathrm{m}$ coronal brain sections of saline-treated (a, c, e) and LY354740-treated (b, d, f) control mice (no EPM). Animal treatments are as described in Figure 3. Scale bar $=100 \mu \mathrm{m}$. Op, optic layer of the superior colliculus; Zo, zonal layer of the superior colliculus.

central visual pathways (Ren and Sagar, 1992; Salminen et al, 1996), suggesting a similar or converging mechanism. Consistent with our results, Lam et al (1999) have reported that systemic LY354740 increased glucose utilization in the SuG. Changes in visual stimulation also induce c-Fos in the DLG, OT, and SuG, but not in the EW (Craner et al, 1992; Montero and Jian, 1995; Lu et al, 2001). The c-Fos induction observed in the present study may be due to changes in neuronal activity in the retina or to local mGlu2 and/or mGlu3 receptor activation. Strong mGlu2/3 receptor immunoreactivity has been detected in the optic layer of the superior colliculus and also in the retina (Koulen et al, 1996; Cai and Pourcho, 1999; Kim and Jeon, 1999). In addition, a high level of LY354740 binding has been detected in the superior colliculus (Wright et al, 2001). Local effect in the SuG is supported by the electrophysiological studies showing that applications of group II mGlu receptor agonists and antagonists on neurons located in the SuG modulate responses to visual stimuli (Cirone and Salt, 2001). Finally, increased activity of thalamic and midbrain regions processing sensory information may be linked to the effects of LY354740 on the arousal or alertness of the animal. For example, the DLG receives inputs from the CeA and LC (DeLima and Singer, 1987; Cain et al, 2002), both of which were activated by LY354740 in the present study. Overall, the functional significance of these changes in sensory and visual brain structures following LY354740 requires further investigation.

It is possible that the activation of visual pathways by systemic LY354740 could produce increased c-Fos expression levels in stress-sensitive brain regions. In addition, the effects of LY354740 on the visual pathways could also affect the EPM behavior, given the importance of visual cues in this test. However, LY354740 is active in several other anxiety tests that are not dependent on visual cues, for example, stress-induced hyperthermia (Spooren et al, 2002) and conflict drinking test (Klodzinska et al, 1999). Moreover, LY354740 administered locally to the hippocampus or amygdala produces anxiolytic-like behaviors (Tatarczynska et al, 2001; Walker et al, 2002), suggesting that the activation of visual regions by systemic LY354740 is most likely unrelated to its anxiolytic actions.

In summary, our results show that the anxiolytic activity of LY354740 on the EPM was associated with the reduction of EPM-induced c-Fos expression in the hippocampus. Interestingly, like clinically effective anxiolytics such as benzodiazepines, LY354740 induced c-Fos expression in various other stress-sensitive regions of the brain such as the lateral portion of the central nucleus of the amygdala. These results support an important role of mGlu2/3 receptors in the modulation of neuronal excitability in stress/fear pathways, and further implicate mGlu receptors as novel targets to treat anxiety disorders.

\section{ACKNOWLEDGEMENTS}

We thank Ms Sarah Sharpe and Dr Laura Nisenbaum for useful advice on the methodology of c-Fos immunohistochemistry.

\section{REFERENCES}

Anwyl R (1999). Metabotropic glutamate receptors: electrophysiological properties and role in plasticity. Brain Res Rev 29: 83-120.

Bachtell RK, Weitemier AZ, Galvan-Rosas A, Tsivkovskaia NO, Risinger FO, Phillips TJ et al (2003). The Edinger-Westphallateral septum urocortin pathway and its relationship to alcohol consumption. J Neurosci 23: 2477-2487.

Beck CHM, Fibiger HC (1995). Conditioned fear-induced changes in behavior and in the expression of the immediate early gene c-fos: with and without diatzepam pretreatment. J Neurosci 15: 709-720.

Bittencourt JC, Sawchenko PE (2000). Do centrally administered neuropeptides access cognate receptors? AN analysis in the central corticotropin-releasing factor system. J Neurosci 20: 1142-1156.

Bradley S, Marino M, Wittmann M, Rouse S, Awad H, Levey A et al (2000). Activation of group II metabotropic glutamate receptors inhibits synaptic excitation of the substantia nigra pars reticulata. J Neurosci 20: 3085-3094.

Cai W, Pourcho RG (1999). Localization of metabotropic glutamate receptors mGluRlalpha and mGlu2/3 in the cat retina. J Comp Neurol 407: 427-437.

Cain ME, Kapp BS, Puryear CB (2002). The contribution of the amygdala to conditioned thalamic arousal. J Neurosci 22: 1102611034.

Cartmell J, Schoepp DD (2000). Regulation of neurotransmitter release by metabotropic glutamate receptors. J Neurochem 75: 889-907.

Chowdhury GMI, Fujioka T, Nakamura S (2000). Induction and adaptation of Fos expression in the rat brain by two types of acute restraint stress. Brain Res Bull 52: 171-182.

Cirone J, Salt TE (2001). Group II and III metabotropic glutamate receptors contribute to different aspects of visual response processing in the rat superior colliculus. J Physiol 534: 169-178. Compaan JC, Groenink L, Gugten Jvd, Maes RAA, Olivier B (1996). $5-\mathrm{HT}_{1 \mathrm{~A}}$ receptor agonist flesinoxan enhances Fos immuno- 
reactivity in rat central amygdala, bed nucleus of the stria terminalis and hypothalamus. Eur J Neurosci 8: 2340-2347.

Conn PJ, Pin J-P (1997). Pharmacology and functions of metabotropic glutamate receptors. Annu Rev Pharmacol Toxicol 37: 205-237.

Craner SL, Hoffman GE, Lund JS, Humphrey AL, Lund RD (1992). c-Fos labeling in rat superior colliculus: activation by normal retinal pathways and pathways from intracranial retinal transplants. Exp Neurol 117: 219-229.

Davis M, Rainnie D, Cassell M (1994). Neurotransmission in the rat amygdala related to fear and anxiety. Trends Neurosci 5: 208-214.

Day HEW, Badiani A, Uslaner JM, Oates MM, Vittoz NM, Robinson TE et al (2001). Environmental novelty differentially affects c-fos mRNA expression induced by amphetamine or cocaine in subregions of the bed nucleus of the stria terminalis and amygdala. J Neurosci 21: 732-740.

DeLima AD, Singer W (1987). The brainstem projection to the lateral geniculate nucleus in the cat. J Comp Neurol 259: 92-192.

Duncan G, Knapp D, Breese G (1996). Neuroanatomical characterization of Fos induction in rat behavioural models of anxiety. Brain Res 713: 79-91.

Ferris P, Seward E, Dawson GR (2001). Interactions between LY354740, a group II metabotropic agonist and the GABAAbenzodiazepine receptor complex in the rat elevated plus maze. J Psychopharmacol 15: 76-82.

Franklin KBJ, Paxinos G (1997). The Mouse Brain in Stereotaxic Coordinates. Academic Press, Inc.: San Diego.

Graeff FG, Silveira MCL, Nogueira RL, Audi EA, Oliveira RMW (1993). Role of the amygdala and periaqueductal gray in anxiety and panic. Behav Brain Res 58: 123-131.

Grillon C, Cordovan J, Levine LR, Morgan III CA (2003). Anxiolytic effects of a novel group II metabotropic glutamate receptor agonist (LY354740) in the fear-potentiated startle paradigm in humans. Psychopharmacology 168: 446-454.

Helton DR, Tizzano JP, Monn JA, Schoepp DD, Kallman MJ (1998). Anxiolytic and side-effect profile of LY354740: a potent, highly selective, orally active agonist for group III metabotropic glutamate receptors. J Pharmacol Exp Ther 284: 651-660.

Hinks GL, Brown P, Field M, Poat JA, Hughes J (1996). The anxiolytics CI-988 and chlordiazepoxide fail to reduce immediate early gene mRNA stimulation following exposure to the rat elevated X-maze. Eur J Pharmacol 312: 153-161.

Hitzemann B, Hitzemann R (1999). Chlordiazepoxide-induced expression of c-Fos in the central extended amygdala and other brain regions of the $\mathrm{C} 57 \mathrm{BL} / 6 \mathrm{~J}$ and $\mathrm{DBA} / 2 \mathrm{~J}$ inbred mouse strains: relationship to mechanisms of ethanol action. Alcoholism: Clin Exp Res 23: 1158-1172.

Hughes P, Dragunow M (1995). Induction of immediate early genes and the control of neurotransmitter-regulated geneexpression within the nervous system. Pharmacol Rev 47: 133-178.

Johnson MP, Kelly G, Chamberlain M (2001). Changes in rat serum corticosterone after treatment with metabotropic glutamate receptor agonists or antagonists. J Neuroendocrinol 13: 670-677.

Kew JNC, Pflimlin M-C, Kemp JA, Mutel V (2002). Differential regulation of synaptic transmission by mGlu2 and mGlu3 at the perforant path inputs to the dentate gyrus and CA1 revealed in mGlu2-/- mice. Neuropharmacology 43: 215-221.

Kilbride J, Huang LQ, Rowan MJ, Anwyl R (1998). Presynaptic inhibitory action of the group II metabotropic glutamate receptor agonists, LY354740 and DCG-IV. Eur J Pharmacol 356: $149-157$.

Kilbride J, Rush A, Rowan M, Anwyl R (2001). Presynaptic Group II mGluR inhibition of short-term depression in the medial perforant path of the dentate gyrus in vitro. J Neurophysiol 85 $2509-2515$.
Kim M-A, Jeon C-J (1999). Metabotropic glutamate receptor mGluR2/3 immunoreactivity in the mouse superior colliculus: co-localization with calbindin D28K. NeuroReport 10: 1341-1346.

Klodzinska A, Chojnacka-Wojcik E, Palucha A, Branski P, Popik P, Pilc A (1999). Potential anti-anxiety, anti-addictive effects of LY354740, a selective group II glutamate metabotropic receptors agonist in animal models. Neuropharmacology 38: 1831-1839.

Klooster J, Beckers HJM, Vrensen GFJM, VanderWant JJL (1993). The peripheral and central projections of the Edinger-Westphal nucleus in the rat. A light and electron microscopic tracing study. Brain Res 632: 260-273.

Koulen P, Malitschek B, Kuhn R, Wassle H, Brandstatter JH (1996). Group II and group III metabotropic glutamate receptors in the rat retina: distributions and developmental expression patterns. Eur J Neurosci 8: 2177-2187.

Kozicz T (2003). Neurons colocalizing urocortin and cocaine and amphetamine-regulated transcript immunoreactivities are induced by acute lipopolysaccharide stress in the EdingerWestphal nucleus in the rat. Neuroscience 116: 315-320.

Kozicz T, Yanaihara H, Arimura A (1998). Distribution of urocortin-like immunoreactivity in the central nervous system of the rat. J Comp Neurol 391: 1-10.

Krukoff TL, Harris KH, Jhamandas JH (1993). Efferent projections from the parabrachial nucleus demonstrated with the anterograde tracer Phaseolus vulgaris-leucoagglutinin. Brain Res 30: 163-172.

Lam AGM, Monn JA, Schoepp DD, Lodge D, McCulloch J (1999). Group II selective metabotropic glutamate receptor agonists and local cerebral glucose use in the rat. J Cereb Blood Flow Metab 19: 1083-1091.

Levine LR, Gaydos B, Sheehan D (2001). The mGlu2/3 receptor agonist, LY354740, reduces panic anxiety induced by $\mathrm{CO}_{2}$ challenge in patients diagnosed with panic disorder. Neuropharmacology 43: 294.

Lister RG (1987). The use of a plus-maze to measure anxiety in the mouse. Psychopharmacology 92: 180-185.

Lu B, Lund RD, Coffey PJ (2001). Basal increase in c-Fos-like expression in superior colliculus of royal college of surgeons dystrophic rats can be abolished by intraocular injection of tetrodotoxin. Neuroscience 107: 109-115.

Marek G, Wright R, Schoepp D, Monn J, Aghajanian G (2000). Physiological antagonism between 5-hydroxytryptamine(2A) and group II metabotropic glutamate receptors in prefrontal cortex. J Pharmacol Exp Ther 292: 76-87.

McKitrick DJ, Krukoff TL, Calaresu FR (1992). Expression of c-fos protein in rat brain after electrical stimulation of the aortic depressor nerve. Brain Res 599: 215-222.

Moga MM, Weis RP, Moore RY (1995). Efferent projections of the paraventricular thalamic nucleus in the rat. J Comp Neurol 359: 221-238.

Monn JA, Valli MJ, Massey SM, Wright RA, Salhoff CR, Johnson BG et al (1997). Design, synthesis, and pharmacological characterization of (+)-2-aminobicyclo[3.1.0]hexane-2,6-dicarboxylic acid (LY354740): a potent, selective, and orally active group 2 metabotropic glutamate receptor agonist possessing anticonvulsant and anxiolytic properties. J Med Chem 40: 528-537.

Montero VM, Jian S (1995). Induction of c-fos protein by patterned visual stimulation in central visual pathways of the rat. Brain Res 690: 189-199.

Neugebauer V, Zinebi F, Russell R, Gallagher J, Shinnick-Gallagher P (2000). Cocaine and kindling alter the sensitivity of group II and III metabotropic glutamate receptors in the central amygdala. J Neurophysiol 84: 759-770.

Pitkanen A, Savander V, LeDoux JE (1997). Organization of intraamygdaloid circuitries in the rat: an emerging framework for 
understanding functions of the amygdala. Trends Neurosci 20: 517-523.

Ren T, Sagar SM (1992). Induction of c-fos immunostaining in the rat brain after the systemic administration of nicotine. Brain Res Bull 29: 589-597.

Robbe D, Alonso G, Chaumont S, Bockaert J, Manzoni O (2002). Role of $\mathrm{p} / \mathrm{q}^{-\mathrm{Ca}^{2+}}$ channels in metabotropic glutamate receptor 2/ 3-dependent presynaptic long-term depression at nucleus accumbens synapses. J Neurosci 22: 4346-4356.

Ryabinin AE, Criado JR, Henriksen SJ, Bloom FE, Wilson MC (1997). Differential sensitivity of c-Fos expression in hippocampus and other brain regions to moderate and low doses of alcohol. Mol Psychiatry 2: 32-43.

Sagar SM, Price KJ, Kasting NW, Sharp FR (1995). Anatomic patterns of Fos immunostaining in rat brain following systemic endotoxin administration. Brain Res Bull 36: 381-392.

Salminen O, Lahtinen S, Ahtee L (1996). Expression of Fos protein in various rat brain areas following acute nicotine and diazepam. Pharmacol Biochem Behav 54: 241-248.

Scanziani M, Salin PA, Vogt KE, Malenka RC, Nicoll RA (1997). Use-dependent increases in glutamate concentration activate presynaptic metabotropic glutamate receptors. Nature 385: 630-634.

Schaffhauser H, Richards JG, Cartmell J, Chaboz S, Kemp JA, Klingelschmidt A et al (1998). In vitro binding characteristics of a new selective group II metabotropic glutamate receptor radioligand, $\left[{ }^{3} \mathrm{H}\right] \mathrm{LY} 354740$, in rat brain. Mol Pharmacol 53: 228-233.

Schoepp DD (2001). Unveiling the functions of presynaptic metabotropic glutamate receptors in the central nervous system. J Pharmacol Exp Ther 299: 12-20.

Schoepp DD, Jane DE, Monn JA (1999a). Pharmacological agents acting at subtypes of metabotropic glutamate receptors. Neuropharmacology 38: 1431-1476.

Schoepp DD, Levine LR, Gaydos B, Potter WZ (2003). Metabotropic glutamate receptor agonists as a novel approach to treat anxiety/stress. Stress 6: 189-197.

Schoepp DD, Marek GJ (2002). Preclinical pharmacology of mGlu2/3 receptor agonists: novel agents for schizophrenia? Curr Drug Targets 1: 215-225.

Schoepp DD, Monn JA, Marek GJ, Aghajanian G, Moghaddam B (1999b). LY354740: a systemically active mGlu2/3 receptor agonist. CNS Drug Rev 5: 1-12.

Shekhar A, Keim SR (2000). LY354740, a potent group II metabotropic glutamate receptor agonist prevents lactateinduced panic-like response in panic-prone rats. Neuropharmacology 39: 1139-1146.

Shigemoto R, Kinoshita A, Wada E, Nomura S, Ohishi H, Takada $M$ et al (1997). Differential presynaptic localization of metabotropic glutamate receptor subtypes in the rat hippocampus. J Neurosci 17: 7503-7522.

Singewald N, Sharp T (2000). Neuroanatomical targets of anxiogenic drugs in the hindbrain as revealed by Fos immunocytochemistry. Neuroscience 98: 759-770.
Skelton KH, Nemeroff CB, Knight DL, Owens MJ (2000). Chronic administration of the triazolobenzodiazepine alprazolam produces opposite effects on corticotropin-releasing factor and urocortin neuronal systems. J Neurosci 20: 1240-1248.

Spooren WPJM, Schoeffter P, Gasparini F, Kuhn R, Gentsch C (2002). Pharmacological and endocrinological characterisation of stress-induced hyperthermia in singly housed mice using classical and candidate anxiolytics (LY314582, MPEP and NKP608). Eur J Pharmacol 435: 161-170.

Stone EA, Zhang Y (1995). Adrenoceptor antagonists block c-fos response to stress in the mouse brain. Brain Res 694: 279-286.

Sun N, Cassell MD (1993). Intrinsic GABAergic neurons in the rat central extended amygdala. J Comp Neurol 330: 381-404.

Sun N, Yi H, Cassell MD (1994). Evidence for a GABAergic interface between cortical afferents and brainstem projection neurons in the rat central extended amygdala. J Comp Neurol 340: $43-64$.

Tamaru Y, Nomura S, Mizuno N, Shigemoto R (2001). Distribution of metabotropic glutamate receptor mGluR3 in the mouse CNS: differential location relative to pre- and postsynaptic sites. Neuroscience 106: 481-503.

Tatarczynska E, Klodzinska A, Kroczka B, Chojnacka-Wojcik E, Pilc A (2001). The antianxiety-like effects of antagonists of group I and agonists of group II and III metabotropic glutamate receptors after intrahippocampal administration. Psychopharmacology (Berl) 158: 94-99.

Trimarchi F (1992). Neuro-ophthalmology. Curr Opin Neurol Neurosurg 5: 740-743.

Vaughan J, Donaldson C, Bittencourt J, Perrin MH, Lewis K, Sutton $S$ et al (1995). Urocortin, a mammalian neuropeptide related to fish urotensin I and to corticotropin-releasing factor. Nature 378: 287-292.

Veinante P, Freund-Mercier M-J (1998). Intrinsic and extrinsic connections of the rat central extended amygdala: an in vivo electrophysiological study of the central amygdaloid nucleus. Brain Res 794: 188-198.

Walker D, Rattiner L, Davis M (2002). Group II metabotropic glutamate receptors within the amygdala regulate fear as assessed with potentiated startle in rats. Behav Neurosci 116: 1075-1083.

Weninger SC, Dunn A, Muglia L, Dikkes P, Miczek K, Swiergiel A et al (1999). Stress-induced behaviors require the corticotropinreleasing hormone (CRH) receptor, but not CRH. Proc Natl Acad Sci USA 96: 8283-8288.

Weninger SC, Peters LL, Majzoub JA (2000). Urocortin expression in the Edinger-Westphal nucleus is up-regulated by stress and corticotropin-releasing hormone deficiency. Neuroendocrinology 141: 256-263.

Wright RA, Arnold MB, Wheeler WJ, Orstein PL, Schoepp DD (2001). ${ }^{3} \mathrm{H}$ ]LY354740 binding to group II metabotropic glutamate receptors in rat brain. $J$ Pharmacol Exp Therap 298: 453-460.

Yokoi M, Kobayashi K, Manabe T, Takahashi T, Sakaguchi I, Katsuura $\mathrm{G}$ et al (1996). Impairment of hippocampal mossy fiber LTD in mice lacking mGluR2. Science 273: 645-647. 